\title{
A UNIVERSIDADE PÚBLICA EM DEBATE NO CENÁRIO INTERNACIONAL
}

\author{
Wrana MaRia PaniZZI
}

\begin{abstract}
R E S U M O Há décadas o mundo universitário brasileiro mantém boas relaçōes de cooperação e intercâmbio acadêmicos no plano internacional. Tais relaçôes têm se revelado de grande importância, proporcionando aos nossos professores e pesquisadores condiçōes de diálogo e trabalho visando a exploração das fronteiras do conhecimento. Desse ponto de vis$t a$, a dimensão internacional da educação e da pesquisa parece absolutamente evidente. $O$ mesmo não se pode dizer a propósito do debate envolvendo a Universidade como instituição. $O$ artigo apresenta um panorama da evolução desse debate na cena internacional desde a Conferência Mundial sobre Educação Superior, realizada em Paris em 1998.
\end{abstract}

P A L A V R A S - C H A V E Universidade pública; educação superior; internacionalização da educação superior; Conferência Mundial sobre Educação Superior; Organização Mundial do Comércio.

A educação e o conhecimento sempre foram estratégicos para o desenvolvimento das nações. Os Estados Unidos, a União Européia e o Japão gastam $80 \%$ de tudo o que se investe em pesquisa no mundo. Isso não acontece, evidentemente, por acaso, nem foi resultado de um movimento gestado da noite para o dia. Entretanto, na última década, o valor econômico e a importância da educação e do conhecimento para as sociedades ganharam notável visibilidade - trata-se de um debate que, definitivamente, não mais se restringe ao intramuros dos campi universitários.

Há várias décadas, pesquisadores e professores universitários brasileiros mantêm boas relaçôes de cooperação e intercâmbio acadêmico no plano internacional, particularmente com universidades norte-americanas, inglesas e francesas, responsáveis pela formação de parcela significativa dos nossos doutores, mas também com universidades alemãs e japonesas e, mais recentemente, por paradoxal que isso possa parecer, com universidades do mundo ibero-americano - Portugal, Espanha, México, Uruguai, Argentina, Chile e outros países. Para a Universidade pública brasileira, historicamente, a cooperação acadêmica internacional tem-se revelado de grande importância, tanto por atualizar nossos professores e pesquisadores como por lhes proporcionar condições de diálogo e trabalho visando a exploração das fronteiras do conhecimento. Desse ponto de vista, a dimensão “internacional" da educação e da pesquisa parece absolutamente evidente. O mesmo não se pode dizer, lamentavelmente, no que se refere à reflexão sobre a Universidade como "instituição". Nesse aspecto, o debate internacional ainda é pouco conhecido no Brasil, inclusive nos meios universitários.

A concepção da Universidade como instituição não é tema "para especialistas" e deveria interessar vivamente ao conjunto da comunidade universitária. Infelizmente, é pre- 
1 A iniciativa do secretariado da Organização Mundial do Comércio é tratada em detalhes por Marco Antônio Rodrigues Dias, ex-diretor da Divisão de Ensino Superior da Unesco e um dos organizadores da Conferência Mundial de Paris: "Educação Superior: bem público ou serviço comercial regulamentado pela OMC?", in Wrana Maria Panizzi (Org.), Universidade - Um lugar fora do poder, Porto Alegre, Ed. da UFRGS, 2002, p.31109.

2 Essa reunião teve lugar na Universidade Federal do Rio Grande do Sul, entre 25 e 27 de abril de 2002, envolvendo a participação de quase cinqüenta reitores, representando universidades de 13 países. Um excelente resumo desse encontro foi organizado por Sílvia Maria Rocha e Carlos Alexandre Netto: Universidade pública, educacão e desenvolvimento - III Cumbre, Porto Alegre, UFRGS, 2002. ciso admitir isso com franqueza, não é o que está acontecendo. O propósito dessa minha breve comunicação é compartilhar com os colegas um pouco do que tenho apreendido sobre o tema nos últimos seis anos, período em que, na condição de reitora de uma Universidade pública brasileira, tive oportunidade de participar de uma série de encontros e reunióes organizados justamente com o propósito de tratar dos destinos do ensino superior no mundo "globalizado".

\section{8: CONFERÊNCIA MUNDIAL DE PARIS E OMC}

O ano de 1998 foi marcado por dois episódios de grande relevância. No início de outubro daquele ano realizava-se em Paris, sob os auspícios da Unesco, a Conferência Mundial sobre Educação Superior. Naquela ocasião, mais precisamente no dia 9 de outubro, representantes de mais de 180 países aprovaram a "Declaração Mundial sobre Educação Superior no Século XXI: Visão e Ação". Cabe lembrar que a Conferência de Paris foi precedida por reuniōes preparatórias (Havana, novembro de 1996; Dakar, abril de 1997; Tóquio, julho de 1997; Palermo, setembro de 1997; Beirute, março de 1998) e que, tanto a Conferência Mundial como a Declaração então aprovada sistematizaram uma concepção de "educação superior" amplamente debatida por pesquisadores, professores e dirigentes universitários das mais diferentes partes do mundo. No centro da Declaração de Paris encontram-se, sem dúvida, as definiçōes do conhecimento como patrimônio social e da educação como bem público - "dever do Estado e direito de todos", podemos ler na Declaração. Entretanto, desde setembro do mesmo ano de 1998, quando se ultimavam os preparativos para a realização da Conferência de Paris, o secretariado da Organização Mundial do Comércio - OMC propunha a regulamentação da educação superior como serviço comercial - objeto de negociação no âmbito do Acordo Geral sobre o Comércio de Serviços (General Agreement on Trade in Services). ${ }^{1}$

Enquanto a concepção de educação superior definida pela Conferência de Paris é retomada em diversos outros encontros internacionais, como veremos a seguir, a OMC dá curso a sua iniciativa e articula adesōes, encontrando apoio particularmente entre universidades dos Estados Unidos, Austrália e Nova Zelândia. De fato, no contexto brasileiro e mesmo latino-americano, a regulamentação da educação superior como serviço comercial somente passou a ser mais amplamente debatida recentemente, mais precisamente a partir de abril de 2002, quando da realização da III Reunião de Reitores de Universidades Públicas Ibero-Americanas ${ }^{2}$ - a "Cumbre", como é conhecida entre os seus participantes.

\section{DA CONFERÊNCIA DE PARIS À III CUMBRE}

Algumas das conclusões da Conferência Mundial de Paris merecem ser aqui brevemente relembradas, como também o fato de que elas resultaram de um debate que envolveu a participação de 115 ministros de Estado e cerca de quatro mil especialistas em Educação:

- fazer valer, também no que se refere ao ensino superior, a Declaração Universal dos Direitos Humanos, afirmando que ela é um direito de todos;

- reforçar a relação entre ensino e pesquisa, observando as demandas do desenvolvimento local, regional e nacional;

- promover, no âmbito das instituições de ensino superior, o respeito da ética, do rigor científico e do trabalho inter e transdisciplinar; 
- promover iniciativas concretas com o propósito de diminuir a distância entre os países desenvolidos, países em desenvolvimento e países pobres no domínio do ensino superior e da pesquisa.

A educação, além de estratégica para o desenvolvimento das nações, é um "direito humano", afırmava a Declaração de Paris. Não há ensino superior de qualidade sem investimento em pesquisa. A ética é condição para o rigor científico. Patrimônio da humanidade, o conhecimento não pode portanto ser prisioneiro do "mercado", indicava a mesma Declaração. Daí a importância da presença do Estado nesse domínio, como agente financiador do "serviço público da Educação", reconheciam os participantes da Conferência. Estaríamos diante de mais uma declaração de "boas intenções"? É provável que tenha sido esse o significado da Declaração de Paris para uma parcela de seus signatários. Para outros, entretanto, ela representou uma grande oportunidade, na medida em que estabelecia uma vigorosa agenda de compromissos e reorientava o debate sobre o ensino superior e a produção do conhecimento em direção diversa daquela então apontada pelos críticos da presença do Estado na economia e em outros setores da sociedade, incluindo o âmbito da educação.

A importância da agenda de compromissos construída em Paris ficou evidente já no encontro Universidade, Globalização e Identidade Ibero-Americana, realizado nos dias 20 e 21 de novembro de 1998, em Córdoba, na Argentina, por ocasião das comemorações dos oitenta anos do célebre Manifesto de Córdoba. A Declaração de Paris seria tomada por muitos participantes daquele encontro como uma espécie de atualização do Manifesto publicado em 1918. Do encontro realizado na Argentina resultou a chamada "Declaração de Córdoba”, na qual, fazendo eco aos compromissos estabelecidos em Paris, o ensino superior é abordado como, entre todos, um dos mais importantes "direitos humanos". ${ }^{3} \mathrm{O}$ encontro foi importante porque deu impulso à nascente articulação universitária ibero-americana, levada adiante por organizações como a Associação de Universidades Grupo Montevidéu (AUGM), sob a liderança de Jorge Brovetto, e o Centro Extremeño de Estudios e Cooperación con Iberoamérica (CEXECI), dirigido por Miguel Rojas Mix.

Poucos meses depois, em 20 de fevereiro de 1999, na Espanha, em Cáceres, capital da província de Extremadura, novamente a comunidade universitária encontra motivos para reafirmar os compromissos de Paris: a chamada "Declaração de Extremadura", documento lá firmado por reitores e autoridades universitárias, expressa a vontade de cooperação para debater e implementar aqueles compromissos no contexto ibero-americano.

Passados alguns anos, não me parece um exagero afirmar que, a partir dos encontros de Córdoba e Cáceres, articulou-se um novo espaço de intercâmbio internacional, voltado para o debate da Universidade como instituição. Um dos resultados desse processo seria a realização das "Cumbres" - dos encontros periódicos de reitores de universidades públicas ibero-americas.

A primeira Cumbre teve lugar entre os dias 3 e 5 de agosto de 1999, na mais tradicional das universidades públicas do Chile, a Universidade de Santiago. Vale a pena mencionar aqui pelo menos um ponto do "Acordo de Santiago": " "o público é o que pertence a todo povo; a universidade pública é a que pertence à cidadania e está a serviço do bem comum; a universidade estatal é a que pertence ao Estado-nação, ela pode não ser pública se não cumprir seu compromisso social, mas, em contrapartida, a universidade pública sempre será estatal ou pública e autônoma por lei”, define o documento firmado no Chile, aprofundando os termos da Declaração de Paris e refletindo sobre as singulari-
3 A Declaração de Córdoba e 0 encontro realizado naquela cidade foram objeto de extensa reportagem realizada pelo jornal da Universidade Federal do Rio Grande do Sul - "A revolta de Córdoba"; "De Paris a Córdoba", Jornal da Universidade, novembro de 1998, p.4-5.

4 Ver "Universidades públicas ibero-americanas reafirmam sua identidade $e$ missão", Jornal da Universidade (UFRGS), agosto de 1999, p.4. 
5 Sobre essa reunião e suas conclusões, ver "Universidade e Ciência na América Latina", Jornal da Universidade (UFRGS), novembro de 1999, p.3; "Falta de vontade política detém avanço da ciência no continente", Jornal da Universidade (UFRGS), dezembro de 1999, p.4.

dades da vida universitária no mundo ibero-americano, que contempla os mais diversos vínculos institucionais.

Pouco antes da primeira Cumbre de Reitores, realizava-se em Budapeste, entre os dias 26 de junho de $1^{\circ}$ de julho de 1999, a Conferência Mundial sobre Ciência e Tecnologia, promovida pela Unesco com propósitos semelhantes aos da Conferência Mundial sobre Educação Superior. Os documentos firmados durante a Conferência de Budapeste não contestaram os termos dos compromissos assumidos em Paris um ano antes. Bem ao contrário disso, aqueles compromissos foram então mais uma vez claramente reafirmados quando, por exemplo, recomenda não apenas que as nações destinem "pelo menos" $1 \%$ do Produto Interno Bruto para investimentos em ciência e tecnologia mas também quando sugere que, para tais fins, devem ser destinados preferencialmente "recursos próprios", como expressão de soberania - e não dinheiro originado de financiamentos externos. Os resultados da Conferência de Budapeste logo serão repercutidos pela comunidade universitária no encontro Universidade e Ciência na América Latina, realizado nos dias 18 e 19 de novembro de 1999 em Porto Alegre, na Universidade Federal do Rio Grande do Sul. A declaração final desse encontro é mais um testemunho de que, mesmo em contexto adverso, é possível construir uma sólida agenda de compromissos. ${ }^{5}$

É interessante finalmente observar que, na segunda Cumbre de reitores de universidades públicas ibero-americanas, realizada na Universidade de Buenos Aires em outubro de 2000, o tema da regulamentação do ensino superior como serviço comercial esteve absolutamente ausente do debate. Com efeito, a reunião de Buenos Aires ainda se caracterizaria pela sistematização e aprofundamento das resoluçōes e compromissos estabelecidos nos encontros anteriores. Assim, embora a iniciativa da OMC já fosse do conhecimento de alguns especialistas bem informados, ela somente chamará maior atenção da comunidade universitária a partir da terceira Cumbre, realizada em Porto Alegre em abril de 2002. A marcha desses acontecimentos nos parece, por si só, motivo para inquietação. Ainda mais se considerarmos que as negociaçóes da OMC prosseguem e que $o$ tema, embora mais visível, ainda não despertou o interesse que merece. Quanto à proposta da OMC, a sucinta "Carta de Porto Alegre", firmada no dia 27 de abril de 2002 por reitores de quase cinqüenta universidades de 13 países do mundo ibero-americano, é bastante clara:

Reitores, diretores de instituições e associaçōes de educação superior e autoridades acadêmicas, reunidos na Universidade Federal do Rio Grande do Sul, em Porto Alegre, por ocasião da III Cumbre Ibero-americana de Reitores de Universidades Públicas, manifestam sua profunda preocupação frente às políticas implementadas pela Organização Mundial do Comércio (OMC), que favorecem a comercialização internacional dos serviços de educação, assemelhando-os a simples mercadorias. Os poderosos interesses que sustentam estas políticas pressionam pela transformação da educação superior num lucrativo mercado de âmbito mundial e pela desregulamentação e eliminação de todo controle de qualidade de natureza legal, política ou fiscal.

A proposta de entregar ao livre comércio a educação superior se inscreve num processo continuado de drásticos cortes no financiamento público e de fomento à globalização da educação privada, levando a que os Estados abandonem sua função política específica de orientação, direção e gestão em áreas de sua responsabilidade social. Estas proposiçôes ferem seriamente as políticas de eqüidade, indispensáveis para o equilíbrio social, em especial 
nos países em desenvolvimento, e necessárias para corrigir as desigualdades sociais, tendo sérias conseqüências para nossas identidades culturais. Elas perturbam, igualmente, a consolidação e a transmissão dos valores éticos e culturais, afetando nossas aspirações de alcançar uma sociedade mais democrática e justa através de um desenvolvimento sustentável, compromissos da educação superior, cuja missão específica se assenta na concepção do conhecimento como bem social destinado à melhoria da qualidade de vida de nossos povos função esta que o ensino superior, em hipótese alguma, poderá cumprir se for transformado em simples mercadoria ou objeto de especulação no mercado, através de sua comercialização internacional. Entre os graves problemas que acarretam tais proposições, cabe mencionar ainda a uniformização acrítica da educação e o grave dano que isso significa para a soberania nacional e dos povos.

Por estas razões, os reitores e acadêmicos ibero-americanos aqui reunidos, lembrando os compromissos assumidos pelos governos e pela comunidade acadêmica internacional em outubro de 1998, na Conferência Mundial do Ensino Superior de Paris, no sentido de considerar a educação superior como um bem público, alertam a comunidade universitária e a sociedade em geral sobre as conseqüências nefastas dessas políticas, e requerem aos governos de seus respectivos países que não subscrevam acordos nessa matéria no contexto do Acordo Geral sobre o Comércio de Serviços (GATS) da OMC.

O ensino superior e a pesquisa científica movimentam, hoje, bilhões de dólares. Também por isso vivemos um tempo em que as universidades públicas, responsáveis por mais de $90 \%$ da pesquisa realizada no Brasil, tornaram-se elas próprias objeto da chamada globalização. A elaboração da "Carta de Porto Alegre" teve o propósito de chamar a atenção para uma negociação que, até o momento, se faz à margem das universidades.

\section{DESAFIOS DA UNIVERSIDADE PÚBLICA}

As resoluçōes da Conferência Mundial de Paris e a abordagem do ensino superior como "serviço comercial" definem concepções que, independentemente do andamento das negociações conduzidas pela OMC, irão balizar o debate sobre o destino da Universidade Pública brasileira nos próximos anos.

A Universidade pública brasileira tem muitos problemas e, como sabem os que têm a responsabilidade de dirigi-la, estes não serão resolvidos somente através do - absolutamente necessário! - aumento de recursos. Nos últimos anos, nossas dificuldades agravaram-se no plano financeiro (ver Gráfico 1) e também institucional. Parte dessas dificuldades devem-se a fatores externos à vida universitária; outra parte, entretanto, importante admitir isso claramente, encontra razões em nossos próprios disfuncionamentos e, sobretudo, na fragmentação crescente e na perda de legitimidade da Universidade pública como "projeto social". 
Gráfico 1 - Total de recursos para efetiva manutenção das IFES (1990-2001), excluindose recursos diretamente arrecadados.

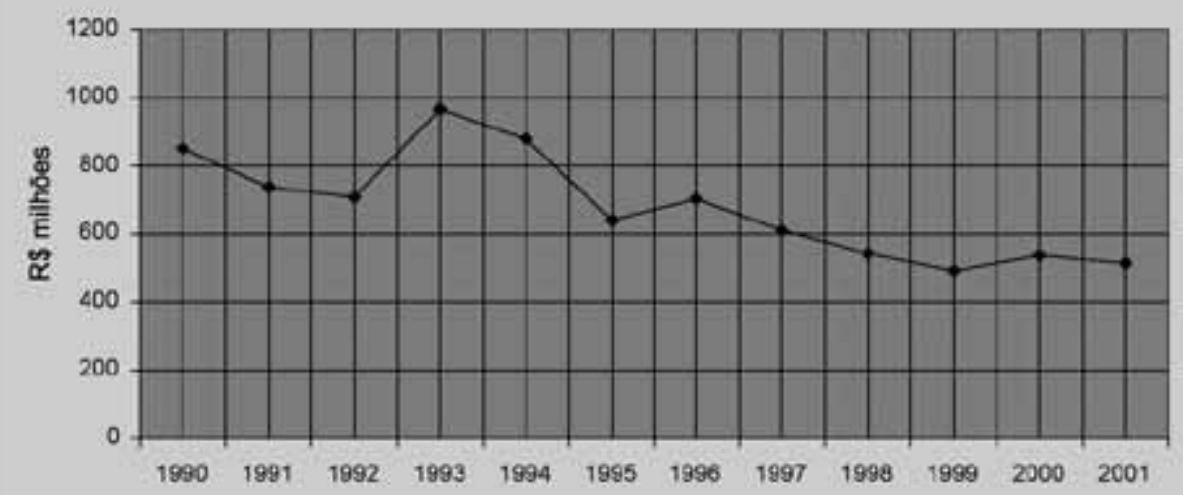

Fonte: Execução Orçamentária apurada pela STN (1990-1994) e Execução Orçamentária da União (19952001), apud Nelson Cardoso Amaral, Tese de Doutorado.

De uma perspectiva histórica ampla, o sistema de ensino superior brasileiro nasceu fragmentado, consolidou-se a partir dos anos 50 como sistema público e expandiu-se de maneira notável na última década do século XX sob a hegemonia do setor privado. Para citar um único exemplo, entre os anos de 1994 e 1999, isto é, em apenas meia década, o número de vagas oferecidas pelo ensino privado quase duplicou. Em 1998, somando-se universidades, associações de faculdades e instituiçôes isoladas, o Brasil contava com 973 instituições de ensino superior, entre as quais somente 209 eram públicas. A despeito dessa notável expansão do sistema, calcula-se que, hoje, somente $13 \%$ da população brasileira com idade entre 18 e 24 anos freqüenta algum curso superior. $\mathrm{O}$ que nos parece ainda mais desafiador é que, no ano 2000 , apenas $68 \%$ das matrículas oferecidas pelo setor privado foram de fato ocupadas (ver Tabela 1 ).

Tabela 1 - Graduação: vagas oferecidas, candidatos inscritos e estudantes matriculados em instituições de ensino superior brasileiras em 2000

\begin{tabular}{lcrr}
\hline & \multicolumn{3}{c}{ Instituições de ensino } \\
\hline Ensino de graduação & \multicolumn{1}{c}{ Total } & Públicas & \multicolumn{1}{c}{ Privadas } \\
\hline Vagas oferecidas & 1.216 .287 & 245.632 & 970.655 \\
\hline Candidatos inscritos & 4.039 .910 & 2.178 .918 & 1.860 .992 \\
\hline Estudantes matriculados no $1^{\circ}$ ano & 897.557 & 233.083 & 664.474 \\
\hline
\end{tabular}

Fonte: Censo do Ensino Superior - Inep/MEC - Brasília (2001).

A história nos mostra que, no Brasil, o ensino público e o privado sempre foram, por assim dizer, "complementares", na medida em que o setor público jamais pode ou teve o propósito de mobilizar recursos para financiar integralmente a educação superior. Contudo, diante da expansão verificada na última década e ante as desigualdades sociais existentes no País, não é difícil concluir que a sociedade brasileira não dispõe de um sistema de ensino superior verdadeiramente acessível "a todos".

Para os que pensam que o ensino superior e o conhecimento são estratégicos para o desenvolvimento das nações, para os que acreditam que a Universidade pública bra- 
sileira é uma experiência que merece ser continuada e fortalecida, a década que se inicia reserva, portanto, grandes desafios. Por um lado, para ampliar sua legitimidade como projeto social, a Universidade pública precisa voltar a crescer, precisa retomar a liderança na expansão do conjunto do sistema - e isso não irá acontecer sem o apoio da sociedade. Por outro lado, a Universidade pública precisa se repensar profundamente como instituição, abrindo-se ainda mais para a sociedade, escutando suas demandas, construindo um novo projeto acadêmico, questionando processos de avaliação que privilegiam o mérito individual em detrimento do trabalho coletivo. Se não enfrentar tais desafios, a Universidade pública, que ontem deixou de ser referência para a expansão do sistema de ensino superior, amanhã poderá perder o que possui de mais precioso: o reconhecimento da sociedade brasileira como referência de qualidade.

Tenho insistido na idéia de que a Universidade pública é fundamental para a sociedade brasileira, não somente porque ela é depositária do melhor que produzimos no terreno das artes, da cultura e das ciências, mas sobretudo porque é lugar da diversidade cultural e da pluralidade ideológica, do debate e do diálogo que constroem sujeitos e coletividades, da crítica comprometida com a ética, que busca ser verdadeira e justa. Creio que o "novo" encontra-se precisamente nesta valorização da Universidade como res publi$c a$ - como construção coletiva que atravessa governos e gerações. Se de fato é assim, cabe à Universidade pública a iniciativa de propor uma profunda reflexão sobre o destino da pesquisa e do ensino superior no País, reunindo em torno de si amplas forças sociais, econômicas e políticas. Empreender tal iniciativa, promover uma reflexão "pra valer" sobre o conjunto de suas atividades, envolver neste debate a comunidade universitária e a sociedade, parece-me ser esse o grande desafio da Universidade pública brasileira. Se enfrentarmos este desafio, nos libertaremos do "conjuntural" e a Universidade pública encontrará forças para se refazer como projeto social.

Para enfrentar nossos problemas, precisamos, antes, defini-los com clareza, porque assim nos tornamos mais conscientes daquilo que queremos e de nossas responsabilidades. José Saramago, em 1999, quando recebeu o título de doutor honoris causa de nossa Universidade, ${ }^{6}$ pronunciou uma frase que, mais do que qualquer outra, resume meu sentimento diante do horizonte que se descortina para a Universidade pública brasileira: "Reivindiquemos os nossos direitos, sim senhor, reivindiquemo-los todos os dias, aqui e onde quer que seja, mas reivindiquemos também, para os assumir completamente, os nossos deveres".

A B S T R A C T The Brazilian universities have had good relations of cooperation and academic exchange at international level for decades. These relations are of paramount importance to advance the conditions of dialogue and work of our professors and researchers, aiming at exploring the frontiers of knowledge. From this standpoint, the international dimension of education and research is quite obvious. However, this does not seem to be the case when the debate involves the University as an institution. This article presents a view of the evolution of this discussion in the international scene since the World Conference on Higher Education, held in Paris in 1998.

K E Y W O R D S Public university; higher education; internationalization of higher education; World Conference on hHigher Education; World Trade Organization.
6 Ver Tania Franco Carvalhal (Org.), Saramago na Universidade, Porto Alegre, Editora da UFRGS, 1999.

Wrana Maria Panizzi é reitora da Universidade Federal do Rio Grande do Sul. E-mail: reitora@ufrgs.br

Artigo recebido para publicação em novembro de 2002. 